\title{
Comparative Research and Analysis of the Quantity of Engineering under Construction Project Based on BIM Technology
}

\author{
Yuping Bai ${ }^{1}$, Dong Wang ${ }^{2}$, Cheng Jiang ${ }^{1}$ \\ ${ }^{1}$ Xuzhou University of Technology, Xuzhou, Jiangsu Province, China \\ ${ }^{2}$ Post Office of Xuzhou, Xuzhou, Jiangsu Province, China
}

Keywords: BIM technology; quantities; Revit; Glodon; Sware; comparison and analysis

\begin{abstract}
An increasing number of software are put into practice as the intensive promotion of BIM technology. The accuracy of quantities arouse the attention of public. This paper focuses on making an accurate analysis on quantities measured through six methods: Revit software, Glodon civil engineering software, Sware civil engineering software, Revit-Glodon civil engineering software, Revit-Sware civil engineering software and manual output.
\end{abstract}

\section{Introduction}

Deeply influenced by the reform and development of construction industry in developed countries, BIM technology has been popularized in the field of construction engineering in recent years. In view of its application and development, the Ministry of Housing and Urban-Rural Development began to study the development of BIM technology in the field of construction industry in 2011, and issued several related policies to publicize this technology, so as to increase the attention of the building field and relevant departments. Generally speaking, the application of BIM has transferred from the design stage to the construction stage, but the application depth and level are far from enough. The application of BIM in the construction stage is still in its exploratory stage with only a few cases.

The development and application of BIM is profoundly changing the cooperation methods in construction projects. But in China, there are still many obstacles in its application. Through this research, we can find that BIM technology is more like a resource and data integration platform. Now the popular concept of BIM5D means to add data about time and funds into the three-dimensional model. It is also the embodiment of big data in construction industry. It is not the restructuring of construction industry, but the integration of various aspects include three dimensional models, time and funds. The purpose of this paper is to find out the relationship between data, then find out irregular parts and correct them, so as to achieve the optimization of building.

\section{Project Profile}

This project is an applied research based on BIM real-time model. It is carried out in the shared practice training base of Jiangsu Vocational Institute of Architectural Technology. The base is located in the northwest corner of the school, and includes three projects of No. 1 training building, No. 2 training building and the service building.

The main object of this analysis is the service building, which adopts the commonly used framework. The research results of this project are more universal and representative, and have reference significance.

\section{Research Methods and Tools}

Revit software is designed for building information model (BIM); it includes the design for architecture, structure, as well as mechanical and electrical installation. Now the software is commonly used in China.

Sware BIM- Revit Sware three-dimensional for Revit software is the first domestically developed 
platform based on Revit; it is compatible with the Revit platform.

Glodon civil engineering software uses multiple quantity calculation methods include CAD map calculation, drawing input calculation, form input calculation and so on.

Sware software realizes the eight functions in one platform, namely earthwork calculation, structural calculation, building calculation, decoration calculation, steel calculation, audit and quantity check, progress management and CAD platform.

\section{Research Process}

\subsection{Appearance inspection}

On the basis of Revit modeling, Revit, Glodon civil engineering and Sware civil engineering are used to inspect the appearance.

\subsection{Wan Ting VR model checking}

VR roaming inspection. The Wan Ting VR equipment is used for 3D display. The model is checked in a three-dimensional space from outside to inside, in order to minimize the model error.

Field measurement and inspection. In order to improve the accuracy of manual output, the project team and its auxiliary team carry out field measurement and inspection. The project team verify and proofread the project quantity for many times.

Through the comparison of measured data and manual quantity, a convincing building model reference quantity is finally obtained.

\section{Comparison of Quantities of Revit, Glodon and Sware}

Basic quantities. As shown in Table 1, only the quantities of J4-2500*3100 works are completely identical. The quantities of other three components in basic Revit models are relatively large.

Table 1 Comparison of basic quantities

\begin{tabular}{|c|r|r|r|r|r|r|}
\hline $\begin{array}{c}\text { Name of the } \\
\text { component }\end{array}$ & \multicolumn{1}{|c|}{ Revit } & Revit-Sware & Revit- Glodon & \multicolumn{1}{c|}{ Sware } & Glodon & $\begin{array}{c}\text { Manual } \\
\text { output }\end{array}$ \\
\hline $\mathrm{J} 1-3900 * 3900$ & 183 & 183.2 & 183 & 181.8 & 181.8 & 181.8 \\
\hline $\mathrm{J} 2-3800 * 3800$ & 7.98 & 7.98 & 7.98 & 7.92 & 7.92 & 7.92 \\
\hline $\mathrm{J} 3-2500 * 2900$ & 3.63 & 3.63 & 3.63 & 3.60 & 3.60 & 3.60 \\
\hline $\mathrm{J} 4-2500 * 3100$ & 3.84 & 3.84 & 3.84 & 3.84 & 3.84 & 3.84 \\
\hline
\end{tabular}

The quantities of column. It can be found that the quantities of engineering are the same. The exact reason is that the quantities of columns are directly determined by intercepting areas and heights; other factors do not need to be considered. Software provides the same result on the modeling features, quantity rules, as well as mapping and transformation of columns. The quantities derived from Sware, Glodon and Revit based platforms are identical. The results are shown in Table 2.

Table 2 Comparison of column quantities

\begin{tabular}{|c|r|r|r|r|r|r|}
\hline $\begin{array}{c}\text { Name of the } \\
\text { component }\end{array}$ & Revit & Revit-Sware & Revit- Glodon & Sware & Glodon & \multicolumn{2}{l|}{$\begin{array}{l}\text { Manual } \\
\text { output }\end{array}$} \\
\hline Kz1 & 1.19 & 1.19 & 1.19 & 1.19 & 1.19 & 1.19 \\
\hline Kz2 & 2.38 & 2.38 & 2.38 & 2.38 & 2.38 & 2.38 \\
\hline Kz3 & 5.4 & 5.4 & 5.4 & 5.4 & 5.4 & 5.4 \\
\hline
\end{tabular}

The quantities of walls. Problems occur in the contrast of wall engineering quantities. The quantity of Revit is obviously larger than that of other methods. The engineering quantity of Revit includes the engineering quantity of thermal insulation layer. Revit- Sware is lack of coal gangue brick (exterior wall) part. The quantities of Sware and Glodon are relatively accurate. The results are shown in Table 3. 
Table 3 Comparison of wall quantities

\begin{tabular}{|c|c|c|c|c|c|c|}
\hline $\begin{array}{c}\text { Name of the } \\
\text { component }\end{array}$ & Revit & Revit-Sware & Revit- Glodon & Sware & Glodon & $\begin{array}{c}\text { Manual } \\
\text { output }\end{array}$ \\
\hline $\begin{array}{c}\text { Integrated inner } \\
\text { and outer walls }\end{array}$ & 1210.66 & 766.9 & 903.36 & 908.64 & 909.38 & 908.24 \\
\hline Outer walls & & $\begin{array}{c}\text { No outer } \\
\text { walls }\end{array}$ & & & & \\
\hline
\end{tabular}

Prominent problems occur in the comparison of engineering quantities of beams. Errors are found in three Revit models with one difference of 23.83 and one definition error. There is a big gap between results of Sware and Glodon software. After analysis, problems are found in the definition of beam and slab. Sware software includes frame beams into the quantity of beam and slab. The results are shown in Table 4

Table 4 Comparison of beam quantities

\begin{tabular}{|c|c|c|c|c|c|c|}
\hline $\begin{array}{c}\text { Name of the } \\
\text { component }\end{array}$ & Revit & Revit-Sware & Revit- Glodon & Sware & Glodon & $\begin{array}{c}\text { Manual } \\
\text { output }\end{array}$ \\
\hline beam & 500.30 & 476.47 & definition error & 440.47 & 79.25 & 79.14 \\
\hline
\end{tabular}

The quantities of slabs. Revit engineering model is relatively accurate in the engineering quantity of slabs. The quantities of Sware and Glodon are different because of their different treatment methods on beam and slab. The results are shown in Table 5

Table 5 Comparison of slab quantities

\begin{tabular}{|c|c|c|c|c|c|c|}
\hline $\begin{array}{c}\text { Name of the } \\
\text { component }\end{array}$ & Revit & Revit-Sware & Revit- Glodon & Sware & Glodon & $\begin{array}{c}\text { Manual } \\
\text { output }\end{array}$ \\
\hline slab & 642.61 & 643.5 & error & 613.36 & 948.5 & 947.35 \\
\hline
\end{tabular}

\section{Comparisons and Summary}

First of all, in the process of engineering quantity comparison, the total amount of Revit project is obviously slightly higher than that of Sware and Glodon. There is no error in the calculation of Sware and Glodon. The accuracy of software output is mainly determined by the modeler.

Secondly, through the comparison of engineering quantities, it can be found that "the secondary development based on Revit software platform" is a more reasonable choice. It is very difficult to achieve seamless docking of two different software platforms; problems of component loss and transformation error will appear in the transformation of plug-in.

\section{Innovative Points of the Research}

First, six groups of engineering quantities are used to make a comparative study: Revit, Glodon civil engineering, Sware civil engineering, Sware for Revit, Glodon GFC conversion and manual calculation. A detailed and accurate comparison of engineering quantities is made. Secondly, based on the actual construction in process: the shared practice training base of Jiangsu Vocational Institute of Architectural Technology, the whole process is traced to ensure the authenticity and accuracy of engineering quantities.

\section{Research Significance}

Through this study, it can be found that the output of domestic cost estimating software is relatively accurate. There is no obvious gap between software. But there are still problems in the transformation of engineering quantity between foreign software and domestic software. For example, big problems are found in the integration of engineering quantity transfer based on GFC standard; the process of transmission still needs to be perfected; the engineering quantity cannot be lossless. Based on these problems, the research group tries to realize nondestructive transmission of engineering 
quantity. The project quantity is transmitted through the design phase and bidding stage; the usage of materials should be strictly controlled to reduce loss. Through the exchange of BIM technology, the information of construction site can be shared; all parties involved can fully understand the engineering situation. The level of decision-making can be raised, while the construction cost can be reduced. The whole process tracking control method can also reduce the differences between parties and shorten the construction period.

\section{Conclusion}

Through this comparison, following conclusions can be drawn. First, the quantity of simple valuation software is relatively accurate; the level of the modeler determines the accuracy of engineering quantity. Second, the mutual conductance of models has great influence on the engineering quantity; the consistency of quantity rules should be fully considered in software docking.

First, the accuracy of software output is briefly discussed. Software calculates engineering quantities according to the rule base (corresponding rules and norms). If the model belongs to conventional component, engineering quantity error will not occur. Errors can only be found in special component processing.

Next is the mutual conductance of models. Why do the engineering quantities of the same model differ? Main problems lie in following aspects. Software identification error: Revit model imports Sware software through mapping. If the naming of Revit is ambiguous, problems will occur in later mapping. Revit model imports Glodon software through plug-in GFC file. Problems of component loss and legality problems can occur in this process. In the final analysis, it is the problem of component identification.

\section{Acknowledgement}

Fund Project: This paper is supported by the Foundation for Research Projects on Safety Risks and Benefits of Construction Enterprises Based on BIM Technology of the Ministry of Housing and Urban-Rural Development.

\section{References}

[1] B. Liu, W. Liu, Application Status and Obstacles Research of BIM in Domestic Construction Industry, J. Construction Economy. 09 (2015).

[2] B.Y. Ji, Z.Y. Jin, Z.Q. Qi, Project Cost of Refinement Management Research Application of BIM, J. Journal of Beijing University of Civil Engineering and Architecture. 04 (2013).

[3] F. Fang, Y.J. Liu, Y.F. Li, B. Xu, Research on BIM based engineering cost fine management, J. Construction Economy. 06 (2014)

[4] J. Li, H.C. Fang, C.H. Luo, Study on BIM based whole process cost management, J. Construction Economy. 09 (2012).

[5] S.J. Zhang, Application of BIM in engineering cost management, J. Construction Economy. 02 (2012).

[6] T.J. Zhang, Application analysis on BIM based project cost management, J. Management \& Technology of SME. 06 (2015).

[7] R. Liu, Y. Xu, Literature review on the application of BIM in engineering cost, J. Project Management Technology. 07 (2014). 